\title{
Vicente Risco. Etnografía y literatura en la configuración nacional de la identidad gallega ${ }^{1}$
}

\section{INTRODUCCIÓN}

Vicente Martínez Risco (Ourense 1884-1963), conocido como Vicente Risco, fue hombre polifacético y curioso que demostró interés por todas las manifestaciones de la cultura. Ensayo, teatro, novela, poesía, historia, biografía, etnografía y mitología fueron, entre otros, el objeto de su pluma incansable. Definidor y teórico del nacionalismo gallego e introductor de la etnografía como disciplina en Galicia, dio lugar a una fecunda escuela etnográfica entre sus contemporáneos de generación y promociones siguientes. Fue fundador y director de la revista Nós (1920-1936), que dio nombre a los hombres de su generación. Además coordinaba en esta revista la sección del "Arquivo filolóxico e etnográfico de Galicia". También fue miembro activo, desde su fundación en 1923, del "Seminario de Estudos Galegos", en el que dirigía la sección de etnografía y folklore. Sus colaboraciones en distintas publicaciones periódicas suman cientos de artículos; en esta época podemos destacar El Miño, Mi Tierra, La Centuria (fundador y director), La Región, A Nosa Terra, La Zarpa, Céltiga, Arquivos do Seminario de Estudos Galegos, Boletín de la Comisión de Monumentos de Orense, Trabalbos de Antropología e Etnología, etc.

Tras la guerra civil, y después de su abandono del nacionalismo, trabaja en el "Centro de estudios de etnología peninsular", continuando con sus investigaciones sobre etnografía gallega. Colabora igualmente en el "Instituto Padre Sarmiento de estudios gallegos", del CSIC, sucesor durante el franquismo del "Seminario", dirigiendo en él la misma sección. Publica importantes trabajos etnográficos en la Revista de Dialectología y Tradiciones Populares. Junto con Otero Pedrayo y otros católicos orensanos funda la revista Misión. Vuelve igualmente a publicar en La Región, Bole-

\footnotetext{
1 Este artículo fue leído en el V Congreso de Antropología (Granada, 1990). Como creo que lo sustancial de su intención original tiene aún cierta vigencia, me he decidido a publicarlo con ligeras correcciones, y la correspondiente actualización bibliográfica. En este sentido, conste mi agradecimiento a Fermín del Pino que, tanto en la primera ocasión como ahora, me ha ofrecido algunas sugerencias.
} 
tín de la Real Academia Gallega, y otras publicaciones de nueva creación como Cuadernos de Estudios Gallegos, Grial, Pueblo, etc.

\section{UNA FIGURA POLÉMICA ${ }^{2}$}

Durante algún tiempo Vicente Risco ha permanecido difuminado, perdido en el silencio y el olvido público que, por significativo, ha incidido en su posterior recuperación. Los intentos por rescatar en Galicia al propio personaje se han caracterizado por un interés insistente hacia su pensamiento e ideología en relación con el nacionalismo o con la literatura, mientras que otras facetas de su obra y su persona no han merecido igual atención. Este es el caso de la etnografía, que, aunque panegíricamente reconocida, no ha sido merecedora de más extensión que breves referencias o apartados dentro de una obra más general, en tanto que su faceta política ha hecho correr mucha tinta ${ }^{3}$.

2 Me gustaría advertir que la visión que ofrezco de Risco y su grupo generacional implica una cierta mirada "exterior": no soy gallego de nacimiento, aunque ya va para quince años que vivo emigrado en Galicia. Esta mirada, no necesariamente privilegiada en tanto contempla al personaje de un modo quizás aún foráneo, no deja de ser al tiempo subjetiva y comprometida, en todo lo que tiene de pasión y descubrimiento personal.

3 Posteriormente a 1990, momento en el que se hizo la primera redacción del presente texto, han visto la luz diversos trabajos con la intención expresa de reconocer e iluminar la dimensión etnológica o antropológica de toda la labor desarrollada por la generación "Nós" y el "Seminario de Estudos Galegos". Sin ánimo de ser exhaustivo mencionaría a Manuel MANDIANES CASTRO, "Folklore, etnografía y etnología en Galicia", Ángel AguiRre BazTán (ed.), Historia de la antropología española (Barcelona: Ed. Boixareu Universitaria, 1992), pp. 57-71; autor que ya con anterioridad había subrayado la plena conciencia del grupo de su quehacer etnográfico. Joaquín RODRíGuez CAMPOS, "La etnografía clásica de Galicia: ideas y proyectos", J. PRAT, U. Martínez, J. Contreras e I. Moreno (eds.), Antropología de los Pueblos de España (Madrid: Taurus, 1991), pp. 97-111, quien en los últimos años ha dedicado especial atención a la historia de la antropología gallega; y, por último, a Jesús DE JUANA, "Risco, Vicente. Etnografía, historia, literatura", C. ORTIZ y L. A. SÁNCHEZ (eds.), Diccionario Histórico de la Antropología Española (Madrid: CSIC, 1994) que se ha centrado en una visión panorámica de la figura de Risco; anteriormente, del mismo autor, Aproximación al pensamiento e ideología de Vicente Risco (1884-1963) (Orense: Diputación Provincial, 1985). También quisiera hacer mención al "Simposio Internacional de Antropoloxia", en memoria de Fermín Bouza-Brey, auspiciado por el Consello da Cultura Galega y celebrado en Santiago y Ponteareas en septiembre de 1992, ya que, en cierto modo y a mi parecer, supuso el definitivo reconocimiento público y unánime, por parte de la antropología gallega, de la dimensión antropológica de los folkloristas y etnógrafos de la Generación Nós. 
Es posible que la importancia relativa de una no sea igual a la de la otra, pero hay un hecho que merece atención y que ha incidido en tan descompensada visión de su figura. Fue innegable su protagonismo en el primer nacionalismo gallego como líder de una tendencia que esquemáticamente se conoce como "culturalista", y que anteponía la recuperación de la realidad históricocultural, con el objetivo de cimentar la fisonomía diferencial de Galicia, a la voluntad política. En contraste, ocurrió luego su deserción del galleguismo y la posterior actitud abiertamente favorable a la Cruzada franquista, hasta extremos que iban más allá de su certeza de la justicia de una causa, pero que aceptaba para salvar el tradicional sentido espiritual y religioso de la vida frente a las fuerzas del materialismo, detrás de las cuales veía los enigmáticos "procesos empregados polo demon. Esta actitud le valió la animosidad de sus antiguos compañeros de generación, en especial de los galleguistas del exilio.

A su muerte, en el prólogo a la obra de Ramón Lugrís, Vicente Risco na cultura galega, escrita con la intención de recuperar al "mestre", al "guieiro", para la cultura gallega, propone Ramón Piñeiro la consideración de su biografía en tres épocas: "A primeira, de formación e percura de sí mesmo chega deica o ano 18; a segunda, de encontro de sí mesmo, é de fecunda plenitude, vai do 18 ó 36; a terceira, de íntima evasión defensiva, vai do 36 ó 63". A esto añade: "resulta craro, xa que logo, que o Risco máis xenuino é o da segunda etapa" ${ }^{4}$ : esto es, la que corresponde a sus preocupaciones nacionalistas. Se evidencia en esta apreciación una lógica maniquea, que reifica el artilugio heurístico. Para más abundar en el tema, agrega Piñeiro: aa imaxe que se basa no conocemento da súa obra i a que se basa no conocemento da súa vida, non sempre cadran" ${ }^{5}$. En la óptica de Piñeiro, la primera posee un vigor interno que raramente alcanzó la segunda. Esta imagen interesada, que apoya su hilo argumental en unas supuestas rupturas biográficas y en una cobardía, fue aceptada dando lugar al reduccionismo político de un hombre que, según su biógrafo Carlos Casares, no fue nunca un entusiasta de la política, sino que fue a ella con muchas reticencias, y con el ideal de regenerar la decadencia de la civilización occidental, clásica y racionalista, con la alternativa de otra, romántica y sentimental, misión que asignó a la Galicia «enxebre" ${ }^{6}$.

4 R. PIÑEIRO, "Prólogo", R. Lugris (ed.), Vicente Risco na cultura galega (Vigo: Galaxia, 1963), pp. XII y XIII.

5 Ibidem, p. XI.

6 Carlos CaSARES, Vicente Risco (Vigo: Galaxia, 1981), pp. 57-58. M. CASADo, "Vicente Risco, o home”, Grial, 86 (1984), 489-505, cita en p. 491. Cuando me encontraba enfrascado en la primera redacción de este trabajo, tuvo lugar una polémica en el 
Enxebre se puede traducir por puro, simple, sin mezcla..., o bien por genuino, enraizado, en tanto que original y originario. Risco ve en lo "enxebre" la expresión simbólico-mnemótica de los arquetipos autóctonos de la cultura gallega, que localiza en lo rústico. El valor de uso que imprime al término tiene su raíz en su personal concepción de lo diferencial y lo inscrito, de modo que nos topamos tanto con Herder como con Jung, para ver en la creación "enxebre" toda producción cultural que se deriva de un primer aferrarse o enraizarse en el orden cultural, tras una inicial conmoción frente al mundo o el paisaje propio cuando aún constituye caos. Por otra parte, dentro de la cultura popular, distingue elementos elaborados, hasta cierto punto, por el pueblo y elementos conservados como sedimento de un saber erudito antiguo; así como elementos "indixenas" o "enxebres" y elementos "alóxenos" o "aculturados", es decir, incorporados a lo que es propio del pueblo gallego. Su idea plural $y$, hasta cierto punto, ecológica de la historia, su difusionismo e historicismo cultural, le llevan a intuir que el hecho de sustraerse al contacto cultural dificulta la constitución de la interioridad de la propia cultura, ya que ésta llega a ser, en gran medida, también constante traducción de lo ajeno ${ }^{7}$. Hombre, como era, "de espírito poliédrico, tan complexo, tan acomodado nas propias contradiccións, como el mesmo confesaban.

La crítica a este punto de vista negativo vino desde planteamientos más rigurosos y exhaustivos, como es el caso de Francisco J. Bobillo, Justo Beramendi, y de Carlos Casares $^{8}$, que coinciden en 1981 en señalar que no existe ruptura entre las distintas etapas, sino un cambio de conducta

Parlamento gallego protagonizada por Manuel Fraga y Xosé Manuel Beiras, que permite hacerse una idea de la vigencia, por lo menos en aquel momento, de la tendencia a reducir a Risco a su mera rúbrica política con el consiguiente tachón sobre la mayor parte de su vida y obra. También es una muestra de la utilización de su memoria como "arma arrojadiza" en el foro político. Las palabras más significativas las pronunció Beiras: "Dixo que era amigo de Risco. Castelao cando se refería a Risco citábao e dicía o seginte: "Dicía Risco, cando Risco era alguén". Vostede foi amigo de Risco cando, segundo Castelao, Risco xa non era ninguén" (Parlamento de Galicia, Diario de sesións, núm. 4, 31 de xaneiro de 1990, p. 93).

7 Leandro CARrÉ Albarellos, contemporáneo de Risco, en su Diccionario traduce 'enxevre' por castizo (puro, libre, y exento de mezcla), y "enxebrismo" por casticismo (virtud del que siente amor por la tierra nativa, su idioma, artes, etc.); como es evidente, su empleo implica una valoración normalmente positiva para referirse a todo lo que se conserva puro y exento de mestizaje. Cf. Diccionario galego-castelán, $8 .^{a}$ ed. (Barcelona: Imp. Igol, Industrias gráficas, 1984).

8 J. G. BERAmENDI, Vicente Risco no nacionalismo galego (Santiago: Cerne, 1981). F. J. BoBillo, Nacionalismo gallego. La ideología de Vicente Risco (Madrid: Akal,1981).

C. CASARES, op. cit. 
que no contradice su ideología subyacente. Los trabajos de Bobillo y Beramendi parten de la ideología de Risco y su relación con el nacionalismo. Bobillo tiene palabras descalificadoras para otros aspectos de su obra: "la historia en general, que Risco nos presenta, está decididamente mediatizada por una radical e irremediable subjetividad interesada. Y otro tanto podría decirse con respecto a todo el conjunto de sus estudios etnográficos y antropológicos, a los que Risco se dedicó durante años" ${ }^{\text {? }}$. Innegable es el hecho de que la obra etnográfica de Risco está sesgada, pero esta conclusión la tenemos de partida al saber que estaba dirigida a fundamentar la nación; éste fue su uso, pero el uso que se hace de la ciencia dice poco de su validez científica. Risco tenía un afán manifiesto de veracidad cuando encaraba la etnografía, por la utilización rigurosa, y nada romántica en este caso, de la metodología que consideraba más adecuada.

Beramendi, más desapasionado, puntualiza que su objetivo es solamente la actuación política y no la total y compleja personalidad de Risco. Por último, otra opinión: Carlos Baliñas considera que Risco no es reducible al papel de un ideólogo político ni es lícito interpretarlo desde un sistema doctrinal, y acaba proponiendo una reflexión sobre las relaciones del intelectual y la política ${ }^{10}$.

\section{LA CONTRIBUCIÓN INICIAL DE VICENTE RISCO, EN CONTEXTO NACIONALISTA}

En una aproximación más grata a Risco, se le podría considerar 'continuador' de una tradición historiográfica gallega, en la que los historiadores, siguiendo la moda de las historiografías de otras partes de España, concibieron la historia como apología, como "instrumentum honoris" de las instituciones y la población gallega. Esta historiografía sufre una transformación, pasando a ser una "mitoloxización histórica ó servicio dun proxecto político" que dará lugar al provincialismo con Faraldo, y al regionalismo con Murguía ${ }^{11}$. En este sentido, la aportación de Vicente Risco y sus compañeros de generación a esta tradición consiste en la adecuación de instrumentos más avanzados y científicos para cimentar la especificidad cultural gallega. Esta iniciativa es autodidacta en muchos

9 BOBILlO, op.cit., p. 155.

10 Beramendi, 1981, op. cit., p. 16. Cf. también C. Baliñas, "A filosofía política de Vicente Riscon, Grial, 86 (1984), 392-411.

1 X. R. BARREIRO FERnáNDEZ, "A historia da historia", X. CASTRO y J. DE JuANA (eds.), IV Xornadas de bistoria de Galicia (Orense: Diputación Provincial, 1988), pp. 17-72. 
sentidos, aunque se pueda hablar de su sólida y heterogénea formación intelectual como bagaje académico para abordar unas tareas que la Universidad, como institución, no abordaría hasta los años setenta.

El legado de Murguía no era escaso: determina cuatro categorías o "elementos nucleares" de la nacionalidad: raza, idioma, territorio y el "volkgeist" herderiano, en el sentido de carácter o alma del pueblo. El lugar de la historia para Murguía es documentar la permanencia en el tiempo de estos elementos. La génesis de la nacionalidad está en la raza céltica. En definitiva, influencias herderianas, el historicismo de Savigny y las teorías raciales de Gobineau ${ }^{12}$. Por su parte, Risco va a definir la nación gallega desde la tierra, la raza, la lengua, la organización social, la mentalidad y el sentimiento. La raza es celta, de alma romántica y lírica. La Lengua es "o elemento máis espiritual, dígase cultural, da nosa vida" ${ }^{13}$ y es de vital importancia para los pueblos, solo ella puede contener cultura en sí misma y solo con una cultura propia puede un pueblo figurar en el mundo y en la historia. Define al hombre gallego como un "homo infimae latinitatis", en un intento de conciliar la contradicción entre el origen latino de la lengua y su preconcepción sobre el origen celta de la cultura. Y la sociedad gallega es un ejemplo de sedentarización rural, con base en la parroquia y la casa-vivienda, que es el vínculo entre el hombre y el paisaje, además de elemento fundamental de toda cultura.

Risco y sus compañeros de generación habilitan dos instrumentos fundamentales para ir al encuentro de las señas de identidad: la revista Nós y el Seminario de Estudos Galegos. Las tareas del Seminario se planifican desde una concepción interdisciplinar, al servicio de la constatación del "feito diferencial" de la cultura gallega. Las diversas secciones dan contenido a las correspondientes categorías culturales: etnografía y folklore, geografía, prehistoria, filología, etc. Por otra parte, las tareas se planifican en jornadas, como estudios de conjunto, con reuniones interáreas e idas al campo: en una concepción similar a la Institución Libre de Enseñanza, en todas las cuales intervienen gentes del lugar. El paradigma de esta concepción metodológica lo constituyó Terra de Melide (1933). Similar planteamiento sigue la obra dirigida por Otero Pedrayo, Historia de Galiza (1962).

La aportación más específica de Vicente Risco es la etnografía. Su mejor conocimiento de la disciplina, sobre la que asentará posteriormente su

12 BARREIRO, op. cit., 1988.

13 V. RISCO, "O idioma galego na nosa vida e na nosa cultura", F. FERNÁNDEZ DEL RiEgo, Vicente Risco. Escolma de texto (La Coruña: Real Academia Gallega, 1981), pp. 35-49; p. 37. 
pensamiento galleguista, coincide con la decisión de Risco de dar un cambio a su vida. Había estudiado Derecho en Santiago e ingresado en el cuerpo de funcionarios de Hacienda en Orense. Insatisfecho como funcionario, sus colaboraciones periódicas en El Miño y Mi Tierra no le ofrecían compensación suficiente, por lo que a sus treinta años decide cursar estudios en la Escuela Superior de Magisterio, de Madrid. La consecuencia más importante de esa estancia madrileña (1913-1916) es su aprendizaje formal de la etnografía, con quien sería su maestro Luis de Hoyos Sáinz. Posteriormente, en 1930, iría pensionado a Alemania para estudiar igualmente etnografía y folklore.

Vicente Risco, al igual que sus compañeros de generación, consideraba el método histórico-cultural de León Froebenius como el más ajustado para sus prospecciones etnográficas; iba de manera especial con su concepción de la mitología como parte de un complejo entramado de elementos de cultura con un origen común, que "forman un todo inseparábele, unha figura, unha fisonomía, que ten un estilo, e que ten capacidade d'espansión dentro d'unha área xeográfica determiñada. E o que se chama kulturkreist (circo cultural)" ${ }^{14}$. Este complejo cultural independiente es para Risco la base para la creación y la expresión de un alma diferenciada, que responde a una especial concepción del mundo y a una actitud ante la vida. A este método integraba la antropogeografía de Ratzel y Vidal de la Blache, donde es fácil descubrir a Herder, y también el matiz racial de Gobineau. Este esquema epistemológico sería enriquecido con las aportaciones de Keyserling y, especialmente, Jung, al que consideraba la reacción del espíritu contra el materialismo freudiano; arquetipos e inconsciente colectivo encajan perfectamente en el universo mental risquiano.

Concibe Risco la historia como memoria que tiende al devenir, y lo devenido deviene en naturaleza. No es una ciencia de leyes y causas, sino de hechos. El concepto de "sino" le parece el más dinámico para referir los hechos, pues indica un sentido, una dirección, una duración. Su objeto es la evolución de la vida social y cultural de los hombres. Por "social" entiende grupos humanos; por cultural, los productos y bienes culturales, divididos estos últimos en espirituales y materiales. Los valores a que responden grupos y bienes dan lugar en cada raza, pueblo o nación, a una unidad o "alma colectiva" de la que es expresión perenne la manifestación externa de su vivir, que se plasma en las diferentes creaciones culturales. Así, la etnografía rescata el alma colectiva en el estudio minucioso de las mismas. Hace Risco crítica del concepto de progreso, conce-

14 V. RisCO, "Ensaio d'un programa pró estudo da literatura popular galegan, Nós, 56 (1928), pp. $142-155$; p. 150. 
bido en la idea y en la creencia de una historia universal orientada a Occidente, con desprecio de las otras culturas. Parte de un concepto irreductible de individualidad de las culturas, de clara herencia herderiana, que produce desarrollos particulares dentro de unos ciclos vitales. Ortodoxo católico, concibe también una paradójica ascendencia providencial en la historia. Su lectura muy particular de Vico, y en especial de Spengler, está detrás de alguna de estas concepciones ${ }^{15}$.

La etnografía y el folklore (etnografía espiritual), son ciencias descriptivas: de la cultura material la primera, y de la espiritual la segunda. Es ciencia auxiliar de la historia, aunque independiente de ella. Desde otro punto de vista, considera Risco que forman parte de la etnología, ciencia de los pueblos y su cultura en cuanto estados culturales; e incluso engloba la historia dentro de esta ciencia de contenido muy vasto. Una concepción más particular se percibe en estas palabras de Risco:

[...j a etnografía ven ser o estudo fisionómico das manifestacións culturás d'un pobo, coma espresión da sua i-alma, un pobo sendo un estilo de vida, unha especial aititude por frente ao mundo, que se revela nas creacións enxebres e moi especialmente na maneira de resolver os probremas primarios d'orde material ou espritual. A impresión inicial que o mundo (como peisaxe) fai na i-alma d'un pobo, "el primer temblor del alma ante el caos", asegún a espresión de Ortega Gasset, determiña pra sempre a cultura material e espritual d'ise pobo. Esa impresión primeira esprésase simbólicamente nas creacións enxebres, que son os emblemas da i-alma criadora, tanto máis craros canto máis primarios, canto máis achegados á aquil pirmeiro contaito do esprito ca peisaxe ${ }^{16}$.

Risco privilegia la etnografía, consciente de su quehacer concreto, de la particularidad de su objeto: "non se trata de facer un estudo etnolóxico, sinón, como acabamos de decir, un cadro etnográfico que axude dalgún xeito a expricación da nosa historia; non hemos expricar, sinón sinxelamente describir ${ }^{17}$. A nadie, no obstante, se le oculta que toda descripción lleva implícita una interpretación: su misma estructura narrativa interpreta e implica preconcepciones. El particular universo simbólico de Risco tiñe su etnografía. El elemento celta, objeto de las pesquisas prehistóricas de Cuevillas, y sobre el que se afirma la raza como origen de la peculiar historia gallega - historia que es memoria del espíritu originario de la raza-, modula y da sentido a muchas de sus descripciones etnográficas.

15 V. Risco, Elementos de metodología de la bistoria (La Coruña: Nós, 1928).

16 V. Risco, "Estudo etnográfico da Terra de Melide", en VV.AA., Terra de Melide. (La Coruña, Ediciós do Castro, 1978), pp. 323-434; pp. 325-326.

17 V. RISCO, "Etnografía: Cultura espiritual", R. OTERO PEDRAYO (ed.), Historia de Galiza I (Madrid: Akal, 1979), pp. 255-762; p. 257. 
En su ensayo sobre la literatura popular gallega empieza diciendo: "O tema e o tídoo apropiado pr'esta parola, habia ser: a y-Alma galega na literatura popular. Efeitivamente, eiquí está o qu'importa qu'esa literatura seña a manifestazón d'unha alma sustancial e distinta". Y más adelante, "Os mais letrados atopan sempre qu'esas caraiterístecas de sentimento e pensamento qu'aparecen na nosa literatura sabia e popular, aseméllanse o máis posibele, ás que os escritores antigos e modernos dan coma distintivas da y-alma céltiga ${ }^{18}$.

La historia como memoria está dirigida a comprobar que se mantiene el orden original; dirigida a conservar, a recordar, es una memoria plagada de símbolos mnemónicos. La mitología, que para Risco es la forma natural y primigenia del mundo tradicional de las ideas, "é a forma simbólica incoscente que toman as ideias e as intuiciós dos primitivos" ${ }^{19}$.

En las relaciones entre historia y mito, Risco no duda en asignar al mito el papel de modelo de todo acontecer, "es el arquetipo de la historia" ${ }^{20}$. El acontecer en su configuración se revela predestinado por esas primeras impresiones que expresan las creaciones "enxebres", por aquel primer contacto del espíritu con el paisaje. El mito es el ser y la historia el parecer; aquél subyace a ésta. Es arquetipo y memoria inconsciente, y por tanto, verdad profunda que da sentido y significación a la vida; considera que el mito posee potencia creadora como forma ejemplar que explica y ordena el acontecer ${ }^{21}$. Así, en su Etnografia: Cultura espiritual, dice: "Cando os Mitos son enxebremente autóctonos, responden a unha concepción orixinaria do mundo que unhas veces resulta e outras pode resultar normativa prás creaciós culturás do pobo que a leva dentro" ${ }^{22}$.

Raza y paisaje son dos categorías originarias que hace devenir Risco en sentimiento romántico de la tierra, romanticismo de la raza y "saudaden de la tierra, caracteres diferenciales de la cultura gallega que afloran en su etnografía. Ejemplo singular es el de "Os mouros encantados", que Risco clasifica como raza mítica o semihumana, presente bajo otras formas en las mitologías europeas y aún en la propia gallega. Atendiendo a su carácter, habitan en monumentos antiguos, castros, "mámoasn; poseen

18 V. Risco, op. cit. (1928), p. 142.

19 Ibidem, p. 149.

20 V. Risco, Orden y caos. Exégesis de los mitos (Madrid: Prensa Española, 1968), p. 170 .

21 Ibidem., 1968, pp. 47-48.

22 Risco, op. cit. (1979), p. 268. En la formulación última de estas concepciones en torno al mito y las creaciones "enxebres" se vislumbra a Mircea Eliade. Su hijo Antón Risco dice que éste era uno de los autores que más leía en su vejez. 
tesoros y aparecen humanizados en cuanto moros. No se asemejan a los moros históricos, ni a los de las leyendas épicas, ni practican la doctrina mahometana - beben vino, comen carne de cerdo, etc.-; el nombre de moros - "mouros"-, no indica, pues, el hecho de ser mahometanos sino, simplemente, el de no ser cristianos. Piensa por ello Risco que se asimila al moro con los antiguos, con los paganos, con los extraños, con los otros; y concluye que los moros son las pseudomorfosis de los primitivos habitantes de Galicia que de este modo perviven en la memoria popular, remitiéndonos así a los antiguos celtas ${ }^{23}$.

\section{ETNOGRAFÍA Y LiTERATURA COMO SOlUCión CULTURAL}

Pasada la guerra civil, con el ánimo en mayor sosiego reemprende sus compromisos etnográficos y literarios, evitando los temas políticos. Inevitable es, no obstante, el distanciamiento de los antiguos compañeros en los afanes nacionalistas. Los más cercanos, sus amigos, intentan comprender; y de entre ellos los hay que, de manera incondicional, tratan de rehabilitar su perfil intelectual. Una vez roto su compromiso social, en la glosa y el ensayo encuentra el lugar donde transformar en inspiración literaria "su saber etnográfico, libre de los esquemas prefabricados de los que, según él, se tiene que valer la ciencia. De este modo puede volar más alto y en la glosa, género que gustó de cultivar siempre, encuentra una posibilidad mayor para la referencia autobiográfica, la simple especulación, o la manera más espontánea de expresar su íntima concepción del mundo; en donde la alusión etnográfica se ubica en el espacio poético de un discurso que propone como paradigma para trascender el parecer de las cosas: el arte y la emoción estética.

No es una novedad que Risco vea a su vez en la etnografía una fuente de inspiración literaria, pues ya en 1925, en el número diez de Lar, publicaba dos relatos cortos que evidencian de manera palpable este hecho: O lobo da xente, fábula en torno a las creencias populares gallegas sobre la licantropía como "fada" (predestinación), y $A$ trabe de ouro e a trabe de alquitrán, recreación literaria de las creencias relacionadas con los "mouros" encantados y sus tesoros, combinados implícitamente con los celtas. Reminiscencias etnográficas tiene también el relato A coutada (1926) y la novela $O$ porco de pé (1928); y un largo etcétera que recorre, a través del tiempo, su producción intelectual y literaria.

23 V. RisCo, "Da mitoloxía popular galega. Os mouros encantados", Nós, 43 (1927), pp. $10-15 ; 45$, pp. $2-8$ (1927). 
La novedad ahora reside en su afirmación de individual independencia, como intelectual no comprometido que reivindica el arte por el arte, la pura especulación contra "la presión coactiva de la masa", que expresará en artículos como "Sobre la independencia del escritor" (Libro de las boras, 1961). Pero no podemos llamar 'novedad' tampoco a lo que, en definitiva, es la autoafirmación regresiva a sus orígenes intelectuales; su primer y juvenil contacto con el arte, con la literatura, los mitos, las religiones, con las otras y lejanas culturas. En esa primera época de su vida que precedió a su conversión galleguista, Risco estaba imbuído del sustrato común de ideas que representan Schopenhauer, Hartmann, Nietzsche, Goethe, Ruskin, Carlyle, etc.; es decir, en consonancia con las corrientes del pensamiento que flotaban en el ambiente de principios de siglo, y propiciando una heterogénea pero común visión crítica de la civilización occidental, a la que Risco se adhiere expresando su rechazo con un sentimiento de inadaptación y proclamando la decadencia de Occidente. Leyó a Baudelaire, Verlaine, Mallarmé, Rimbaud, Apollinaire, Novalis, León Bloy, Paladan, Emerson, etc. En general, le fascinan los decadentistas y simbolistas ingleses y franceses, y los románticos alemanes. Se siente más cerca de Oriente que de Occidente, del budismo que del kantismo, y se interesa por todo lo que de exótico tiene lo oriental en sus manifestaciones culturales, mitológicas y religiosas; siente inclinación hacia lo oculto, el misterio y la teosofía.

En este caldo de cultivo germinará su odio permanente estético a todo lo que Occidente representa: clasicismo, racionalismo, positivismo, materialismo e industrialismo, progreso... En definitiva,el espíritu de la Ilustración. Para la mirada crítica de Risco, nuestra civilización de "gusto advenedizo y plebeyo" carece de sentido espiritual, de ahí su decadencia. El mismo concepto de civilización indica un afán de violentar la naturaleza, de romper el orden natural y sustituirlo por mecanismos — prótesis, que diría Freud-, que reflejan solamente la incapacidad para comprenderla ${ }^{24}$.

Como contraste, contempla Risco la ruralidad desde una óptica rousseauniana que le induce a equipararla a la vida primitiva, en oposición de esta manera a la vida civilizada o ciudadana. Gusta de representar esta dicotomía de contrarios por medio de los "símbolos históricos" de Caín y Abel. Caín, fundador de la primera ciudad, como civilizado. Abel, pastor y nómada, como bárbaro: la torre de Babel es el profético símbolo del progreso. Narración bíblica, Rousseau y Buda en la curiosa combinación risquiana vienen a expresar la misma cosa, que se articula en varias

24 V. Risco, Las tinieblas de Occidente (Santiago de Compostela: Sotelo Blanco, 1990), pp. 38-44. 
oposiciones: Oriente-Occidente, bárbaro-civilizado, campo-ciudad... Así dice nuestro autor: "El Contrato Social representa la sustitución de los grupos humanos naturales (tribu, clan y familia) por agrupaciones artificiales $\mathrm{o}$ ciudades. La ciudad es ya el Estado, y el Contrato Social es el origen de la civilización caínita" ${ }^{25}$.

La rusticidad queda identificada como la depositaria del tesoro de las tradiciones y fuente principal de inspiración artística, como único baluarte frente al Estado ilustrado. La concibe, pues, como la memoria que en mitos, leyendas, creencias, usos, preserva la sabiduría tradicional del hombre arcaico, del avasallamiento de la civilización, de la amnesia de los arquetipos, de la pérdida de identidad ${ }^{26}$.

Con la llegada del nacionalismo, lo exótico encontrará su continuidad en lo "enxebre". El prurito individual de originalidad y diferenciación - gustaba de repetir, "ser diferente es ser existente, — lo hace extensivo ahora a la especificidad del colectivo gallego. Pero, evidentemente, la Galicia originaria y genuina será la tradicional y rústica. En el número uno de Nós escribe así: "Oxe chegou á vida na nósa Terra, unha xeneración que se deprocatou do seu imperioso deber social de crearen pra sempre a cultura galega ${ }^{27}$. Este "deber social", que le resulta imperioso ahora a Risco, fue considerado filisteo muy poco tiempo antes, como lo era para él todo compromiso en el arte o la literatura. Así lo había reflejado en 1917 en su "Preludio a toda estética futura", publicado por entregas en la revista La Centuria, del que extraemos estas palabras:

Y bien ¿qué es el arte social? El arte social no es el arte del pueblo; el arte del pueblo, verdadero y único arte democrático, es el folk-lore, y folk-lore es tradición, la tradición más arcaica y más sagrada. [...] Los teóricos del arte social dicen que éste debe expresar las inquietudes y las aspiraciones de la época; que el artista ha de ser portavoz del alma de los pueblos, por su boca ha de hablar la conciencia social ${ }^{28}$.

El compromiso del intelectual con su propia sociedad, era una idea muy común e incluso un ideal a alcanzar en el flujo y reflujo de las ideas del pensamiento europeo de aquellos primeros años del siglo, como lo reflejan las anteriores palabras de Risco. Que esta idea del compromiso del intelectual había tenido amplio eco en España se hace patente, como

25 Ibidem, p. 42.

26 Ibidem, pp. 38-44, y V. RIsco, op. cit., (1968), pp. 184-185.

27 V. Risco, 30/10/20, "Primeiras verbas", Nós, 1 (1920).

28 V. RisCo, La Centuria, 3 (1817), pp. 12-13 (edición facsimilar, Barcelona: Edic. Sotelo Blanco, 1981). 
subraya Fermín del Pino, si ponemos a Risco en relación con la casi coetánea generación del 98: "no en todas las épocas se han sentido tan comprometidos los escritores, con su propia sociedad, como en tiempos de la generación del 98 "29.

No es, por otra parte, el único aspecto que tienen en común esta generación del 98 y la generación Nós, en la que indudablemente se inscribe Risco. La afinidad personal con Unamuno llega a superar las notorias diferencias que los separan: ambos comparten misticismo en el sentimiento del paisaje, panteísmo y religiosidad como expresión de ese sentimiento, importancia capital de la lengua y su relación con el alma de los pueblos... En ambos se observa una cierta oscilación pendular que transforma el acercamiento a Europa en la audaz idea de "españolizarla" o "galleguizarla"; hasta la actitud ante el alzamiento del general Franco contra la República es similar en ambos pensadores. José Luis Varela sintetiza bien esta concomitancia:

\begin{abstract}
Un fondo ochocentista asoma en una serie de parentescos con Unamuno: ensayo con información científica contra la ciencia; gusto por la contradicción y la paradoja; paralelismo entre intrahistoria y mundo de lo rústico; Don Quijote como héroe contra la Razón. Su vinculación a Unamuno nos advierte, precisamente, su verdadera vinculación generacional. Risco, nacido en 1884 pertenece a la promoción de 1914 (Ortega, Pérez Ayala, Marañón, Gómez de la Serna) que, como es sabido, no significa ruptura, sino convivencia continuadora en muchos órdenes con el $98^{30}$.
\end{abstract}

Risco no puede sustraerse del todo a la influencia del medio y, a pesar de sus recelos, asumió un cierto posibilismo filisteo ante la perspectiva de hacer realidad su utopía íntima. Es muy probable, como bien subraya Baliñas, que hacer inteligible a Risco como político sólo resulta posible considerando al Risco total, como contexto; al intelectual que se caracteriza por sus contradicciones, por sus dudas, que tiene una personal convicción con respecto a la vida y al mundo de su entorno; al Risco lector incansable y apasionado, vanguardista, novecentista, tradicionalista, elitista, inadaptado... No es descabellado suponer que en su ideología política incidieran más consideraciones que las explícitamente políticas: “O home de esprito non se perde de todo na obra social", dice el mismo Risco en Nós,

29 Fermín DEL PINO, "Por una valoración antropológica de la obra literaria", Segundas Jornadas de Antropología de Madrid (Madrid: Asociación Madrileña de Antropología, 1990), pp. 115-130; p. 12.

30 J. L. VARELA, "La transfiguración literaria del mundo mítico (El ensayo de Vicente Risco)", pp. 259-297, de La transfiguración literaria (Madrid: Prensa Española,1970), p. 293. 
os inadaptados ${ }^{31}$, publicado en 1933 en la revista Nós (n. ${ }^{\circ}$ 115). Por otra parte, su conversión al nacionalismo iba íntimamente unida a su vuelta a la ortodoxia católica y a su peculiar vivencia religiosa. La política es, pues, concebida por Risco al servicio de algo que la trasciende: la cultura diferencialmente gallega. No fue un buen político, carecía del bagaje teórico necesario para fundamentar una correcta acción en este terreno. Intentar enfocar su figura desde parcelas meramente biográficas, o tomando a priori un posicionamiento político, lleva necesariamente a interpretaciones tendenciosas que desfiguran la dimensión global de su perfil humano.

\section{RISCO Y SU CONTEXTO HISTÓRICO Y DISCIPLINAR}

Una imagen verdaderamente integrada de Vicente Risco no puede prescindir del contexto espacial y temporal en que le tocó vivir, y especialmente del modo personal de vivenciarlo. No se trata tanto de valorar desde el presente su aportación a la ciencia y a la cultura, ni de considerarlo precursor de esto o de aquello. Se trata de situarlo, junto a sus coetáneos, como expresión viva y personalizada de su tiempo. De aquí el interés de su propio punto de vista, de sus ideales íntimos, de su modo de vivenciar el arte, la literatura, la etnografía, el galleguismo o el nacionalismo. En términos generales, las constantes de Risco permanecen a lo largo de los tres períodos en que ha quedado estereotipada su vida, y su obra. Su biografía intelectual debe aportar una imagen particularizada de cómo, por qué y cuándo se dió el hecho etnográfico en Galicia; los objetivos que lo impulsaron y los condicionamientos que lo configuraron.

Risco, reconocido por sus compañeros de generación como impulsor y maestro en las tareas etnográficas, no es el único que practica la disciplina, ocupación común del grupo, cohesionado en torno a la idea colectiva de fundamentar la Nación sobre la base diferencial de la cultura. La clara conciencia generacional no es, sin embargo, fruto de sus actividades

31 Nós, os inadaptados es un ensayo autobiográfico de enorme interés para la comprensión de las contradicciones e inquietudes que le acompañaron a lo largo de su vida, en el que afirma que el bome de esprito tiene dos opciones: o bien persistir en la introversión, o bien extravertirse en la obra social. En el segundo caso su misión es la de guía de los demás, implicando una renuncia al propio "Nirvana". Risco justifica su dandismo, su inadaptación, como algo inherente a su condición de gallego. Su galleguidad, de la que acaba de tomar conciencia, sería la responsable de su rechazo de la Cultura Occidental y de su consiguiente búsqueda alternativa de una "cultura atlántica", en cuya teorización pone todo su empeño. Por eso, su compromiso político no implica renuncia alguna a sus convicciones anteriores, antes bien es la salida coherente a la inadaptación. 
científicas o literarias sino, fundamentalmente, de las políticas. De ahí el rechazo y la posterior tergiversación de la figura de Risco. La etnografía producida por Risco después de la guerra civil, mantiene - con la excepción del uso de la lengua-, las mismas constantes galleguistas de la etapa: en lo que a este campo se refiere, no existió la pretendida "ruptura" biográfica. Se da la paradoja de que Risco vino a contemplar finalmente su compromiso político como una traición a sí mismo, y a sus ideales estéticos. En una carta que escribe a Francisco Fernández del Riego, le dice:

Polo pronto, coido que cheguei, adentro de min, a unha emancipación perfeita de tódo-los deberes, a non ser os que teño con Dios e coa miña familia. Endexamais tiven unha liberdade tan leda e tan lúcida. Traballo me custou tomar posesión de min mesmo, e nono houbera conseguido de non ser un inadaptado $^{32}$.

En esta segunda inadaptación dentro de la soledad, Risco se reafirma en sus convicciones y creencias, que se constituyen las más de las veces como dicotomías, que toman la forma de oposición dentro de un pensamiento maniqueo y agónico. Al espíritu opondrá la materia, al sentimiento la razón, al progreso la tradición, a la ciencia el mito, al diablo Dios. Satanás. Biografia del diablo (1947) es una de las obras más expresivas de la mentalidad risquiana, aunque no sea la primera ni la única vez en que toca la figura del diablo. Etnográficamente lo aborda primeramente en "O demo na tradición popular galega" ${ }^{33}$. No es sólo un recuperador de tradiciones: Risco se identifica con ellas, adopta como propia la mentalidad arcaica y popular. En este sentido, su religiosidad tiene las raíces en el mundo de lo rústico y lo tradicional, donde se da la consonancia entre el hombre y el paisaje. Lo rústico está en contacto con lo originario y lo arquetípico: es la memoria de lo eterno ${ }^{34}$. La cosmovisión risquiana del mundo como apariencia y expiación privilegia "la conciencia como facultad estética" para vislumbrar el ser de las cosas, esto es la intuición artística fundada en la fe, como actitud simpática que cumple una función cognoscitiva. El ideal íntimo de Risco fue poseer el privilegio del artista: no pudo ser pintor -uno de sus frustrados anhelos- y entonces es cuando se aproxima a la literatura.

Expresó siempre una admiración casi envidiosa por Valle-Inclán. Su confianza en la intuición poética como mejor método de conocimiento,

32 Carta de 1/11/48. En C. CASARes, Vicente Risco (Vigo: Galaxia,1981), p. 122.

33 Nós, 30 (1926).

34 V. RISCO, "Lo rústico", Libro de las horas (Orense: Gráficas Tanco, 1961). 
se confirmaba en la persona de Valle: "foi o que máis fondo furóu nos estratos máis acochados da psique galaica" ${ }^{35}$. Más adelante añade: "En todo caso, Valle-Inclán, en lugar de estudiar as superticións galegas dende fóra, como facemos os que seguimos os métodos máis correntes da Etnoloxía, dános a impresión dunha vivencia directa delas" ${ }^{36}$. Risco está convencido de que Valle-Inclán cree en lo que escribe mientras escribe, lo que le permite transmitir ese inigualable verismo a sus descripciones líricas del mundo rural gallego. Fe, simpatía, intuición: he ahí, para Risco, el mejor camino para captar el ser de las cosas. Etnógrafo y literato intercambian experiencias.

La última parte de su vida lo fue de afirmación literaria, y así reclama para la literatura el tratamiento de los mitos: «La única pretensión de este libro es reivindicar para lo sencillamente literario un terreno que le perteneció en otro tiempo -y que ha pasado luego a otras manos-. Tan sólo un simple hombre de letras vuelve a ocuparse de lo que trataron predecesores suyos más sabios y más hábiles" ${ }^{37}$. El acercamiento literario al mito por parte de Risco enlaza con la misma concepción del mito como tautagórico: "descifrar el misterio sería anularlo; nada puede en su reino la razón [...], su sentido es, al mismo tiempo, patente y arcano, evidente para la conciencia interior, y se realiza por sí mismo" ${ }^{38}$.

Aquí la funcionalidad del mito es remitir a lo sagrado, a lo divino y a lo primigenio, lo inconsciente y arquetípico. Para Risco, mitología y poesía son la misma cosa. No es, pues, una elusión del rigor en el tratamiento de los mitos lo que Risco pretende con su acercamiento literario, sino el camino más ágil y acertado para su comprensión.

Nadie puede negar a Vicente Risco su carácter de etnógrafo; pero precisamente por eso quizá lo mejor de su literatura sea su obra etnográfica, sin olvidar sus glosas y el tratamiento de los mitos.

35 V. Risco, "Valle-Inclán e as supersticións de Galicia", Leria (Vigo: Galaxia, 1990), pp. $145-146$.

36 Ibidem, 181.

37 V. Risco, op. cit. (1968), p. 49.

38 V. RIsco, Mitología cristiana (Madrid: Editora Nacional, 1963), p. 55. El símbolo místico es "tautagórico" en tanto se concibe como afirmación de sí mismo y vinculado a lo que expresa de manera "natural", sin una relación externa y arbitraria como el referente en el signo. Es repetición de un mismo arcano (como la tautología de un mismo pensamiento) del que es "hierofanía", por emplear la expresión de Mircea Eliade. No pertenece al orden de la intelección y del concepto, sino al de la voluntad y el sentimiento, por lo que nunca llega a ser estrictamente conocido, aunque pueda ser pensado. 


\section{CONCLUSIONES}

Podríamos concluir que desde la perspectiva antropológica, que hemos querido privilegiar, no existe incoherencia evidente entre vida y obra en la persona de Risco, y parece que tampoco se la vislumbra en su vertiente literaria ${ }^{39}$; discordancia hay más bien en su contacto con la política, en forma de pérdida de identidad personal, pues no podemos olvidar que al final de su vida ${ }^{40}$ observó como "gratuita anomalía" su relación temporal con ella. Esta fue su respuesta a los políticos gallegos. Pero no consideró anómalo su retorno a la actividad intelectual -literaria y etnológica-, ahora ya instalado en su independencia de escritor todavía inadaptado.

Aún conserva el deseo "de pór o pensamento galego en comunicación coas correntes do mundo, co intento de vivir o noso tempo ó noso xeito", sin necesidad de intermediarios, como recuerda en el "limiar" de Leria. El Risco inadaptado y modernista que se asoma a Europa, a las religiones orientales, a las culturas lejanas no occidentales, trae a escena al que sabe incorporar a su práctica vital e intelectual los valores de la modernidad, sin traicionar los ideales de la tradición; y este mismo nos aproxima ya al etnógrafo, armado con los instrumentos metodológicos y el saber cosmopolita adquirido por el viajero, emigrado en Madrid (alumno de Ortega y de Hoyos, asiduo de la tertulia de Pombo...) o Alemania (Mitteleuropa, estudios etnológicos...); fruto maduro que recoge del vanguardista que, asomado al mundo desde Orense, puede contrastar lo ajeno con lo propio para, después, configurar la diferencia, queriendo alcanzar lo universal (eterno), 'enxebre' y rústico, en la particularidad gallega.

39 Confróntese, por ejemplo, la propuesta de Ramiro Fonte de tomar en consideración a otros Riscos distintos, igual o más importantes que el nacionalista, para evitar una visión reduccionista anclada en su corta etapa política, y poder abordar la complejidad laberíntica del pensamiento y la obra risquiana: más cercana a un proyecto estético que político. En general todo el monográfico, dedicado a Risco por la revista $A$ nosa terra, en su conjunto es una invitación a contemplar al personaje desde patrones no simplistas. Pudiéndose alcanzar en una lectura conjunta una imagen más móvil, plural y particularizada de su figura, que contrasta con la visión fija, abstracta y estereotipada que suele ofrecer su lectura exclusivamente ideológica y política. En todo caso, pienso que su reaccionarismo ideológico debe ser un dato para poder recuperar su obra de forma crítica, y no causa de descalificación intelectual o estrecho corsé reductivo. R. FONTE, "Teoría do heterodoxo galego", AA. VV., Monográfico "Vicente Risco arredor de Nós", A nosa terra (Vigo, 1993), pp. 102-105.

40 Leria, passim (1961). 
En un camino de ida y vuelta, este cosmopolita-provinciano ${ }^{41}$ está en las mejores condiciones para iniciar una tarea de recuperación de lo propio, instalado en la saudade que la distancia del inadaptado, también viajero imaginario, le aporta. Aúna, así, la influencia extranjera (lo cosmopolita y universal) y el descubrimiento de la propia originalidad (lo tradicional y particular) en una actitud vital que caracteriza tanto al modernismo, como pone los ráles sobre los que asentará su labor profesional de etnógrafo. Su posición intelectual profunda - que cuestionaba la simplicidad y la homogeneidad culturales que proponía el proyecto liberal, progresista e ilustrado- ofrece una alternativa en la concepción antropológica que innovadoramente se construye desde la particularidad de su objeto, abierta a la diversidad y la diferencia.

La literatura y la etnografía no son en nuestro autor actividades escindidas ni dependientes; sino que una y otra se despliegan paralelas, mutuamente complementarias e intercomunicadas, nacidas del mismo impulso creador que anima al intelectual, y, sin embargo, son dispares en las formas expresivas que adoptan, en la manera rigurosa o libre con que las aborda. No existe compartimentación del conocimiento, sino que se puede contemplar la construcción de la tarea intelectual como totalidad de significación que se vierte en canales, que no confunde pero aproxima, para conferirles el sentido que quiso imprimir a su aventura personal como autor. Nunca el escritor o el novelista pretendieron, en ningún momento, hacer opaco al etnógrafo y el folklorista.

Como conclusión de un quehacer que llenó gran parte de su vida, un año antes de su muerte, publica en Buenos Aires y en gallego la que muchos de sus críticos consideran la culminación de su obra etnográfica: el volumen dedicado a la "Etnografía: cultura espritual" como parte de la Historia de Galiza (1962) dirigida por Otero Pedrayo, que efectivamente constituiría la síntesis sistemática de su ejercicio etnográfico en Galicia. Ninguna de las licencias que se había permitido desde la literatura en el tratamiento de los mitos - para incorporar las regiones del sueño, de lo mágico, lo irracional y lo inconsciente a la superficie de la vida cotidiana - está presente aquí; no porque esté ausente de su síntesis la constelación simbólica y mitológica, sino porque se conduce

41 Ramiro Fonte le califica en similar sentido de provinciano-europeísta, quizás de forma más ajustada al sentir de Risco: que, entre otras cosas, no compartía los ideales cosmopolitas en pro de la desaparición de fronteras o de la fraternidad universal. Sin embargo, no empleó en ese sentido el término, sino en el que expresa su apertura espiritual al mundo, para estar en contacto con todo lo que tiene de novedoso, vanguardista o exótico... o bien con el intento de comunicar la cultura gallega con el universo, sin mediación cultural ajena. 
dentro de los márgenes del canon que había adoptado para esta tarea específica.

Independientemente de que desde el presente se le quiera recuperar como etnólogo o antropólogo, Risco tendió - como he apuntado al principio- a autodefinirse como etnógrafo, quizás porque estaba convencido -como su maestro en el aprendizaje de la disciplina, Hoyos Sáinz- ${ }^{42}$ que su momento era el de la descripción, dejando para más adelante o para otros la tarea explicativa, más específicamente etnológica o (como hoy diríamos) antropológica.

Lejos de toda visión reducionista (y a pesar de su relevancia política o literaria: que ha dado lugar, incluso en el específico campo de nuestro interés, a que sea comentado con más profusión desde presupuestos literarios o nacionalistas que en su vertiente antropológica) considero, para terminar, que Vicente Risco puede y debe ser valorado de pleno derecho por su contribución histórica a la antropología: gallega, hispana y europea.

Carlos Coppel Hidalgo

Universidade de A Coruña

42 Carmen ORTIZ, Luis de Hoyos Sáinz y la antropología española (Madrid: CSIC, 1987), pp. 283-305. 
La figura señera de Vicente Risco es objeto de revisión necesaria, como modo de aproximación a la ingente labor etnográfica desplegada a la sombra del incipiente nacionalismo gallego en los albores del siglo. El indiscutible liderazgo intelectual de Risco, hasta la proclamación de la II República, le permitió propiciar junto a sus compañeros de generación, desde posiciones tradicionalistas y culturalistas, un nacionalismo que se apoyaba en la cultura como hecho diferencial. Ahora bien, frente al juicio corriente que reconstruye su figura principalmente como "hombre político" y divorcia su vida de su obra, se ofrece la oportunidad de recuperar críticamente a este intelectual provinciano de espíritu cosmopolita, desde la coherencia que ofrece su intrincada personalidad, su vida y su obra. Para más allá de todo estereotipo ideológico, poder ofrecer a Risco un espacio normalizado en la historia de la antropología.

The great figure of Vicente Risco ought to be revised in the process of assessing his extensive ethnographic work, done under the shelter of the incipient Galician nationalism of the early 20th century. Risco's intellectual prominence before the years of the Second Republic enabled him to defend, from traditionalist and culturalist positions, a nationalism founded upon the notion that culture is a distinctive fact. He was joined in this endeavor by other members of his generation. The author, who finds fault with the received interpretation of Risco as a "political man" and of his work as something unrelated to his life, attempts to recuperate this provincial as well as cosmopolitan scholar by showing the coherence that his complex personality, life and work reveal. The author's aim is to find for Risco the place in the history of anthropology that he deserves, beyond any ideological branding. 